\title{
Photoperiod-sensitive cytoplasmic male sterile elite lines for hybrid wheat breeding, showing high cross-pollination fertility under long-day conditions
}

\author{
K. Murai $\mathbb{D} \cdot$ H. Ohta $\cdot$ M. Kurushima $\cdot$ N. Ishikawa
}

Received: 22 April 2016/Accepted: 5 September 2016/Published online: 12 September 2016

(C) The Author(s) 2016. This article is published with open access at Springerlink.com

\begin{abstract}
Photoperiod-sensitive cytoplasmic male sterility (PCMS) caused by Aegilops crassa cytoplasm under long-day (LD) photoperiods ( $\geqq 15 \mathrm{~h}$ ) has been proposed as a two-line system for producing hybrid varieties in common wheat (Triticum aestivum). The PCMS line is maintained by self-pollination under short-day (SD) conditions, and hybrid seeds can be produced through outcrossing of the PCMS line with a pollinator line under LD conditions. Maintainer lines of the PCMS lines are not necessary in this system. In our previous study, we developed two PCMS lines with the genetic background of the Japanese wheat
\end{abstract}

K. Murai $(\bowtie)$

Department of Bioscience, Fukui Prefectural University, 4-1-1 Matsuoka-Kenjojima, Eiheiji-cho, Yoshida-gun,

Fukui 910-1195, Japan

e-mail: murai@fpu.ac.jp

H. Ohta

Agricultural Research Institute, HOKUREN Federation of Agricultural Co-operative, Minami 2, Higashi 9,

Naganuma-cho, Yubari-gun, Hokkaido 069-1316, Japan

M. Kurushima

Kitami Agricultural Experiment Station, Agriculture

Research Department, Hokkaido Research Organization, 52 Yayoi, Kunneppu-cho, Tokoro-gun,

Hokkaido 099-1496, Japan

N. Ishikawa

Western Region Agricultural Research Center, NARO, 6-12-1 Nishifukatsu-cho, Fukuyama,

Hiroshima 721-8514, Japan cultivar 'Fukuotome', which showed high male sterility under LD conditions and high seed fertility under SD conditions. These PCMS lines were from a $\mathrm{BC}_{2}$ generation and were not genetically pure. Therefore, we screened the progeny of the $\mathrm{BC}_{2}$ lines, and identified $\mathrm{BC}_{2} \mathrm{~F}_{8}$ lines that showed high male sterility and high cross-pollination fertility under LD conditions and high seed fertility under SD conditions. Furthermore, we screened the pollinator lines suitable for the PCMS system. These PCMS elite lines and selected pollinator lines will be useful for developing hybrid wheat varieties.

Keywords Aegilops crassa - CMS · Hybrid wheat . Photoperiod-sensitive cytoplasmic male sterility .

Triticum aestivum . Wheat

\author{
Abbreviation \\ PCMS Photoperiod-sensitive cytoplasmic male \\ sterility
}

\section{Introduction}

Although bread wheat (Triticum aestivum) is an autogamous plant species, heterosis (hybrid vigor) has been observed in hybrid wheat varieties. For example, in a previous report using Japanese wheat cultivars, we demonstrated that $23 \mathrm{~F}_{1}$ hybrids produced an average of $40 \%$ more than the mid-parent yield (Murai 1997a). Recently, Longin et al. (2012) 
summarized a number of reports and found that heterosis in wheat could range from 3.5 to $15 \%$ in commercial hybrid wheat varieties. A report from the International Maize and Wheat Improvement Center (CIMMYT) in 2011 concluded that hybrid wheat is a promising approach for improving yield potential and stability and for pyramiding stress tolerances (CIMMYT 2011). They suggested that by 2030 a minimum of 15 million hectares of hybrid wheat will be grown in developing countries with a $15 \%$ yield increase over a 4 ton per hectare average yield. They also pointed out that development of cost-effective hybrid wheat systems is necessary.

The main hybrid wheat-growing countries in Europe are France (160,000 ha) and Germany $(25,000 \mathrm{ha})$ that use chemical hybridization agents (CHAs) to produce hybrids (Longin et al. 2012). In Asia, hybrid wheat is mainly cultivated in China (30,000 ha) and India (35,000 ha). Cytoplasmic male sterility (CMS) systems based on Triticum timopheevii cytoplasm is utilized in these countries. In China, genic male sterility (GMS) systems are also used for hybrid seed production. Although hybrid wheat breeding programs have been established for several decades, hybrid wheats still represent only a small fraction of the total wheat sown. Whitford et al. (2013) identified various factors that have limited the use of hybrid wheat: (1) CMS systems are difficult to use due to a lack of effective fertility-restoration genes, (2) GMS systems have largely failed due to problems with fertility restoration, and (3) CHA systems still suffer from problems of toxicity and selectivity.

We proposed an alternative approach for hybrid wheat production using a simple "two-line system" based on photoperiod-sensitive cytoplasmic male sterility (PCMS) resulting from the presence of Aegilops crassa cytoplasm (Murai 2001a). PCMS is induced by long-day (LD) conditions of $15 \mathrm{~h}$ or longer light periods during the floret differentiation stage. PCMS is expressed in the form of homeotic transformation of stamens into pistilloid (pistil-like) structures that is mediated by the A. crassa cytoplasm (Murai et al. 2002). Using the PCMS system, hybrid seeds can be produced through outcrossing of a PCMS line with a pollinator line under long-day conditions ( $\geqq 15 \mathrm{~h}$ light, the natural day length for spring-sown wheat in Hokkaido, Japan). In contrast to the "three-line system" using T. timopheevii cytoplasm (Johnson and Schmidt
1968), the two-line system does not need a maintainer of male sterility because the PCMS line will grow and multiply by self-pollination under shortday (SD) conditions ( $\leqq 14.5 \mathrm{~h}$ light, natural day length for autumn-sown wheat in Honshu, Shikoku and Kyushu, Japan). The PCMS system has the further advantage over other CMS systems of a relatively high level of fertility restoration due to the synergistic effects of SD environmental conditions and effective fertility-restoring gene(s) (Murai 1997a).

We sought to develop practical PCMS lines that show high male sterility under LD conditions and high seed setting rates under $\mathrm{SD}$ conditions and produced two lines, \#6(11)-3 (PCMS 7 line) and \#7(12)-2 (PCMS 8 line); (cr)-Norin 26/Fujimikomugi//3*Fukuotome, that fulfilled these criteria (Murai et al. 2008). The alloplasmic line of the Japanese wheat cultivar 'Norin 26' with A. crassa cytoplasm ((cr)-Norin 26) shows high seed fertility under SD conditions, whereas the alloplasmic line of Fujimikomugi ((cr)-Fujimikomugi) is completely male sterile under LD conditions. 'Fukuotome' is an elite cultivar used for production of Japanese noodles in the western region of Japan. These PCMS lines were the $\mathrm{BC}_{2}$ generation and were not genetically homogenous lines (Murai et al. 2008). From the progenitors of the PCMS 7 and PCMS 8 lines, we selected 14 and 18 lines in the $\mathrm{BC}_{2} \mathrm{~F}_{8}$ generation and examined their agronomic characters under LD conditions at Hokkaido and SD conditions at Fukui. Based on the obtained data, we identified eight promising elite PCMS lines that showed high cross pollination fertility and high male sterility under LD conditions and high seed fertility under SD conditions.

\section{Materials and methods}

Plant materials

Thirty-two PCMS lines were used in this study. These lines have a 'Fukuotome' cultivar genetic background, namely (cr)-Norin 26/Fujimikomugi//9*Fukuotome, and were developed from the $\mathrm{BC}_{2}$ lines \#6(11)-3 (PCMS 7 line) and \#7(12)-2 (PCMS 8 line) (Murai et al. 2008). As controls, cv. 'Fortunato I. Bo. 219' and 'Fukuotome' were used in Hokkaido and Fukui, respectively. 'Fortunato I. Bo. 219' is an Italian hard red spring wheat cultivar and a candidate of the 
pollinator lines for the PCMS system; this line was also used as a pollinator line in crosses to examine the cross-pollination ability in the PCMS lines under LD conditions at Hokkaido.

For screening of pollinator lines suitable for the PCMS system, five alloplasmic lines of hard red spring wheat cultivars were used: (cr)-Norin 26/2*Yumeshiho, (cr)-Norin $26 / 3 *$ Kitami-haru 63 , (cr)-Norin 26/3*Fortunato I. Bo. 219, (cr)-Norin 26/3*Aroora, and (cr)-Norin $26 / 3 *$ Wildcat, which are described as (cr)-Yumeshiho, (cr)-Kitami-haru 63, (cr)-Fortunato I. Bo. 219, (cr)-Aroora, and (cr)-Wildcat, respectively, in the text. The alloplasmic line of Fukuotome, (cr)Norin $26 / 6 *$ Fukuotome $\mathrm{BC}_{5} \mathrm{~F}_{3}$ (described as (cr)Fukuotome), which has no $R f$ gene was used as a comparison of fertility restoration under SD conditions in the alloplasmic lines of pollinator candidates.

Field trials in Hokkaido to examine agronomic characters of the PCMS lines

In April 2015, crossing blocks for the 32 PCMS lines (PCMS 7\#1-\#14, PCMS 8\#1-\#18) and a pollinator line, 'Fortunato I. Bo. 219', were set up at the experimental field of Kitami Agricultural Experimental Station, Hokkaido. The PCMS lines were planted at a $3.5 \mathrm{~cm}$ spacing in a single row which was surrounded on each side by a row of pollinators planted at a $2 \mathrm{~cm}$ spacing.

At the heading stage, the frequency of pistillody was determined in one ear from each of the PCMS 7 and PCMS 8 lines. The frequency of pistillody (\%) was measured as the proportion of pistilloid stamens in the total stamens of the first and second florets in all spikelets in an ear. Culm length (cm) was also measured using the main shoot of three plants in each PCMS 7 and PCMS 8 line.

Five characters were studied in the ear of the main shoot of three plants in each PCMS 8 line (PCMS 8\#1\#18): ear length $(\mathrm{cm})$, spikelet number per ear, grain number per ear, grain number per spikelet, and open pollination fertility (\%). Grain number per spikelet was based on the total number of seeds and spikelets in each ear. Open pollination fertility (\%) was measured as the seed setting rate of the first and second florets of all spikelets. Three ears in each PCMS 8 line were bagged before flowering, and self-fertility (\%) was measured as the seed setting rate. The data for each character were obtained from three plants in each line; the means for each character were used in the analyses of variance.

The 1000-grain weight $(\mathrm{g})$ and volume weight $(\mathrm{g} / \mathrm{L})$ were estimated from the grain number, grain weight and grain volume of five ears in PCMS 8\#12 and 'Fortunato I. Bo. 219'.

Field trials for examining agronomic characters of the PCMS lines in Fukui

Eighteen PCMS 8 lines (PCMS 8\#1-\#18) were grown in the season 2014/2015 at the experimental field in Fukui Prefectural University. The plants were grown with a spacing of $10 \mathrm{~cm}$ in one row. Six characters were measured in each PCMS line and in 'Fukuotome': culm length $(\mathrm{cm})$, ear length $(\mathrm{cm})$, spikelet number per ear, grain number per ear, grain number per spikelet and self-fertility (\%). With the exception of self-fertility, the characters were measured using the main shoot and its ear in each plant. The ear of the second shoot of each plant was bagged before flowering, and self-fertility was estimated by the seed setting rate of the first and second florets of all spikelets. The data for each character were obtained from five plants in each line; the means for each character were used in the analyses of variance (ANOVAs).

Screening of pollinator lines suitable for the PCMS system

Six alloplasmic lines ((cr)-Yumeshiho, (cr)-Kitamiharu 63, (cr)-Fortunato I. Bo. 219, (cr)-Aroora, (cr)Wildcat, and (cr)-Fukuotome) and the corresponding euplasmic lines were grown in the season 2010/2011 at the experimental field in Fukui Prefectural University. Using ears bagged before flowering, self-fertility (\%) and grain number per spikelet were measured. The means for them were used in the analyses of variance (ANOVA).

\section{Statistical analyses}

We screened for significant differences among the PCMS lines and the controls using an analysis of variance (ANOVA). Differences at the $P<0.05$ level were considered significant. We also used a $t$ test to compare seed characters in PCMS 8\#12 and the control. 


\section{Results}

Culm length and frequency of pistillody

in the PCMS lines under LD conditions

The mean culm lengths in 32 PCMS lines (PCMS 7\#114, PCMS 8\#1-18) and in the 'Fortunato I. Bo. 219' pollen parent, grown under LD conditions in Hokkaido, are shown in Table 1. PCMS 7 lines were consistently taller than 'Fortunato I. Bo. 219', and in 8 lines the difference was significant. PCMS 8 lines were shorter than 'Fortunato I. Bo. 219', indicating that they were more suitable for outcrossing as it is better that PCMS lines are shorter than the pollinator line.

The PCMS 7 lines exhibited lower frequencies of pistillody than the PCMS 8 lines (Table 1). Based on plant heights and frequency of pistillody, we excluded PCMS 7 lines as candidates for the elite PCMS lines. Among PCMS 8 lines, PCMS 8\#4, \#5, \#7, and \#13 had a frequency of pistillody of $<55 \%$ and were also excluded. The pistilloid stamen and pistil of a PCMS line together with the pistil of a normal line ('Fortunato I. Bo. 219') are shown in Fig. 1a-c.

Agronomic characters of the PCMS 8 lines under LD conditions

We measured five agronomic characters in the PCMS 8 lines and 'Fortunato I. Bo. 219' (Table 2). The data was analyzed by an analysis of variance, which indicated that 10 PCMS lines had significantly shorter ears and 8 lines had a smaller spikelet number per ear than 'Fortunato I. Bo. 219'. All PCMS lines showed no self-fertility (Table 2), although the frequencies of pistillody were not $100 \%$ (Table 1). This indicated that the PCMS lines produced non-pistilloid stamens together with pistilloid stamens, and that the nonpistilloid stamens did not have functional pollen, i.e., they were male sterile. As the PCMS lines were completely male sterile, then any grains in the ears of PCMS lines must be the result of out-crossing to the pollinator line. Therefore, cross-pollination ability was estimated from the data on grain number per spikelet and open pollination fertility (Table 2). An ANOVA identified significant differences among PCMS lines for cross-pollination ability. As a result, PCMS $8 \# 2$ and \#16, which had $<20$ grains per ear, were excluded as candidates for elite PCMS lines.
Table 1 Culm length and frequency of pistillody in PCMS 7 and PCMS 8 lines under long-day conditions at Hokkaido

\begin{tabular}{|c|c|c|c|}
\hline Line & Culm length $(\mathrm{cm})$ & & Pistillody (\%) \\
\hline Fortunato & $78.4 \pm 0.93$ & & 0.0 \\
\hline PCMS 7\#1 & $81.0 \pm 1.53$ & & 22.2 \\
\hline PCMS 7\#2 & $79.3 \pm 1.67$ & & 40.9 \\
\hline PCMS 7\#3 & $86.7 \pm 2.33^{* *}$ & High & 15.9 \\
\hline PCMS 7\#4 & $82.3 \pm 1.45$ & & 30.0 \\
\hline PCMS 7\#5 & $80.7 \pm 1.20$ & & 27.8 \\
\hline PCMS 7\#6 & $84.7 \pm 1.76^{* *}$ & High & 25.3 \\
\hline PCMS 7\#7 & $85.3 \pm 2.33^{* *}$ & High & 13.6 \\
\hline PCMS 7\#8 & $81.3 \pm 0.88$ & & 22.2 \\
\hline PCMS 7\#9 & $86.3 \pm 1.45^{* *}$ & High & 21.2 \\
\hline PCMS 7\#10 & $89.3 \pm 0.88 * *$ & High & 19.2 \\
\hline PCMS 7\#11 & $83.7 \pm 1.33^{*}$ & High & 28.9 \\
\hline PCMS 7\#12 & $88.3 \pm 1.67 * *$ & High & 19.4 \\
\hline PCMS 7\#13 & $83.0 \pm 1.73^{*}$ & High & 14.8 \\
\hline PCMS 7\#14 & $81.0 \pm 1.00$ & & 25.3 \\
\hline PCMS 8\#1 & $74.3 \pm 2.03$ & & 95.7 \\
\hline PCMS 8\#2 & $70.3 \pm 1.67 * *$ & Low & 63.3 \\
\hline PCMS 8\#3 & $77.7 \pm 0.88$ & & 77.8 \\
\hline PCMS 8\#4 & $72.7 \pm 1.86^{* *}$ & Low & 33.3 \\
\hline PCMS 8\#5 & $77.0 \pm 2.52$ & & 52.7 \\
\hline PCMS 8\#6 & $74.7 \pm 0.33$ & & 58.9 \\
\hline PCMS 8\#7 & $74.3 \pm 2.40$ & & 50.0 \\
\hline PCMS 8\#8 & $76.0 \pm 2.52$ & & 57.5 \\
\hline PCMS 8\#9 & $73.7 \pm 1.20^{*}$ & Low & 67.8 \\
\hline PCMS 8\#10 & $73.0 \pm 0.56^{*}$ & Low & 75.0 \\
\hline PCMS 8\#11 & $79.0 \pm 2.52$ & & 57.4 \\
\hline PCMS 8\#12 & $75.3 \pm 2.03$ & & 79.8 \\
\hline PCMS 8\#13 & $74.7 \pm 1.45$ & & 47.9 \\
\hline PCMS 8\#14 & $73.0 \pm 1.53^{*}$ & Low & 67.8 \\
\hline PCMS 8\#15 & $74.7 \pm 0.33$ & & 77.4 \\
\hline PCMS 8\#16 & $72.7 \pm 2.33 * *$ & Low & 90.8 \\
\hline PCMS 8\#17 & $74.7 \pm 1.76$ & & 94.0 \\
\hline PCMS 8\#18 & $76.3 \pm 0.67$ & & 77.1 \\
\hline
\end{tabular}

* and ** Significantly different at 5 and $1 \%$ level, respectively, compared with 'Fortunato I. Bo. 219' in an ANOVA

Agronomic characters of the PCMS 8 lines under SD conditions

We measured six agronomic characters in PCMS 8 lines and 'Fukuotome', as a control, grown under SD conditions in Fukui (Table 3). The PCMS lines had a 
Fig. 1 a Pistil of normal line. $\mathbf{b}$ and $\mathbf{c}$ Pistil and pistilloid (pistil-like) stamen of PCMS line. d Ears of PCMS line grown under short-day and long-day conditions. e $F_{1}$ seeds obtained by crosspollination between PCMS line and pollinator line under long-day conditions. f Selfed seeds of pollinator line under long-day conditions

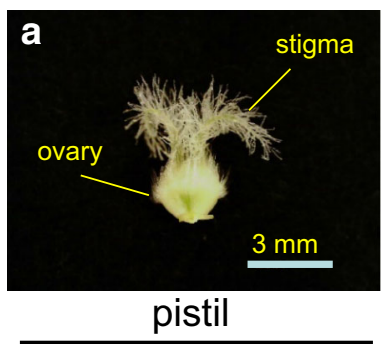

normal line

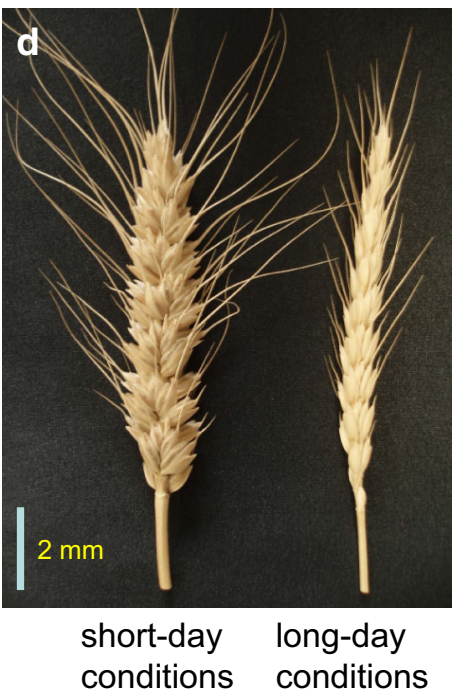

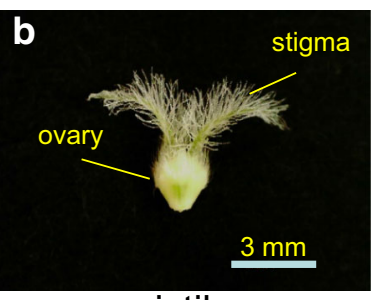

pistil

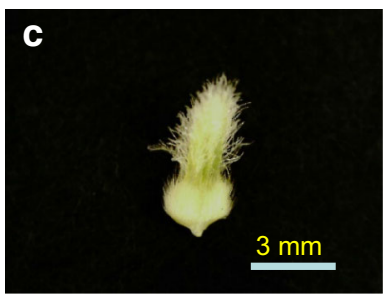

pistil-like stamen
PCMS line
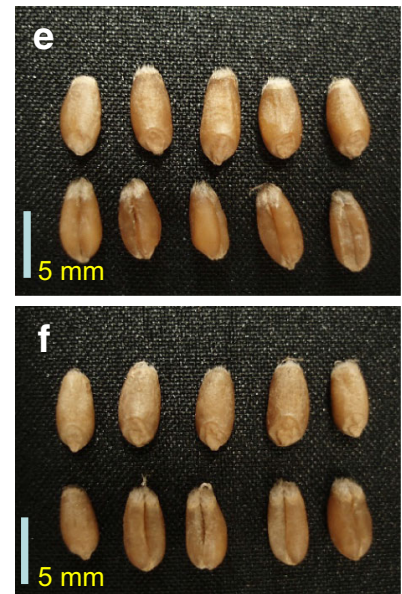

$F_{1}$ seeds of PCMS line

Selfed seeds of pollinator line
'Fukuotome' genetic background. Six PCMS lines had significantly shorter ears and two lines had a smaller spikelet number per ear than 'Fukuotome'. Elite PCMS lines are expected to have high self-fertility under SD conditions because of efficient seed formation. We excluded PCMS 8\#4, \#5, \#7, \#9, \#11, \#13, $\# 14$, \#15, \#16 and \#18 as candidate elite lines as they showed significantly smaller grain numbers per ear compared with the highest value of 54.7 seen in PCMS 8\#3 (Table 3).

Screening candidate elite PCMS lines

Based on the data obtained under LD conditions at Hokkaido and SD conditions at Fukui, our selection procedure left PCMS 8\#1,\#3, \#6, \#8, \#10,\#12 and \#17 as candidate elite lines. The characteristics of a selfed ear in a PCMS line under LD or SD conditions are shown in Fig. 1d. Among the selected seven lines, PCMS 8\#12 was most promising as it showed the highest open pollination fertility (cross-pollination ability) under LD conditions (Table 2) and had a high level of self-fertility under SD conditions (Table 3). PCMS $8 \# 12$ produced good quality $\mathrm{F}_{1}$ seeds under $\mathrm{LD}$ conditions after cross-pollination; these seeds were similar to the selfed seeds of a normal line (Fig. 1e, f). The grains of PCMS 8\#12 exhibited higher 1000-grain and volume weights than the pollinator cultivar 'Fortunato I. Bo. 219' (Table 4).

Screening pollinator lines suitable for the PCMS system

Comparison of self-fertility (\%) and grain number per spikelet between euplasmic and alloplasmic lines of Fukuotome under SD conditions were shown in Fig. 2. The alloplasmic (cr)-Fukuotome exhibited significantly lower fertility $(<60 \%)$ and smaller grain number per spikelet $(<1.5)$ compared with the euplasmic Fukuotome. As Fukuotome has no $R f$ gene(s) against the PCMS, it was fertile but showed low fertility under SD conditions. Contrary to Fukuotome, differences of self-fertility between euplasmic and alloplasmic lines in five cultivars (Yumeshiho, 


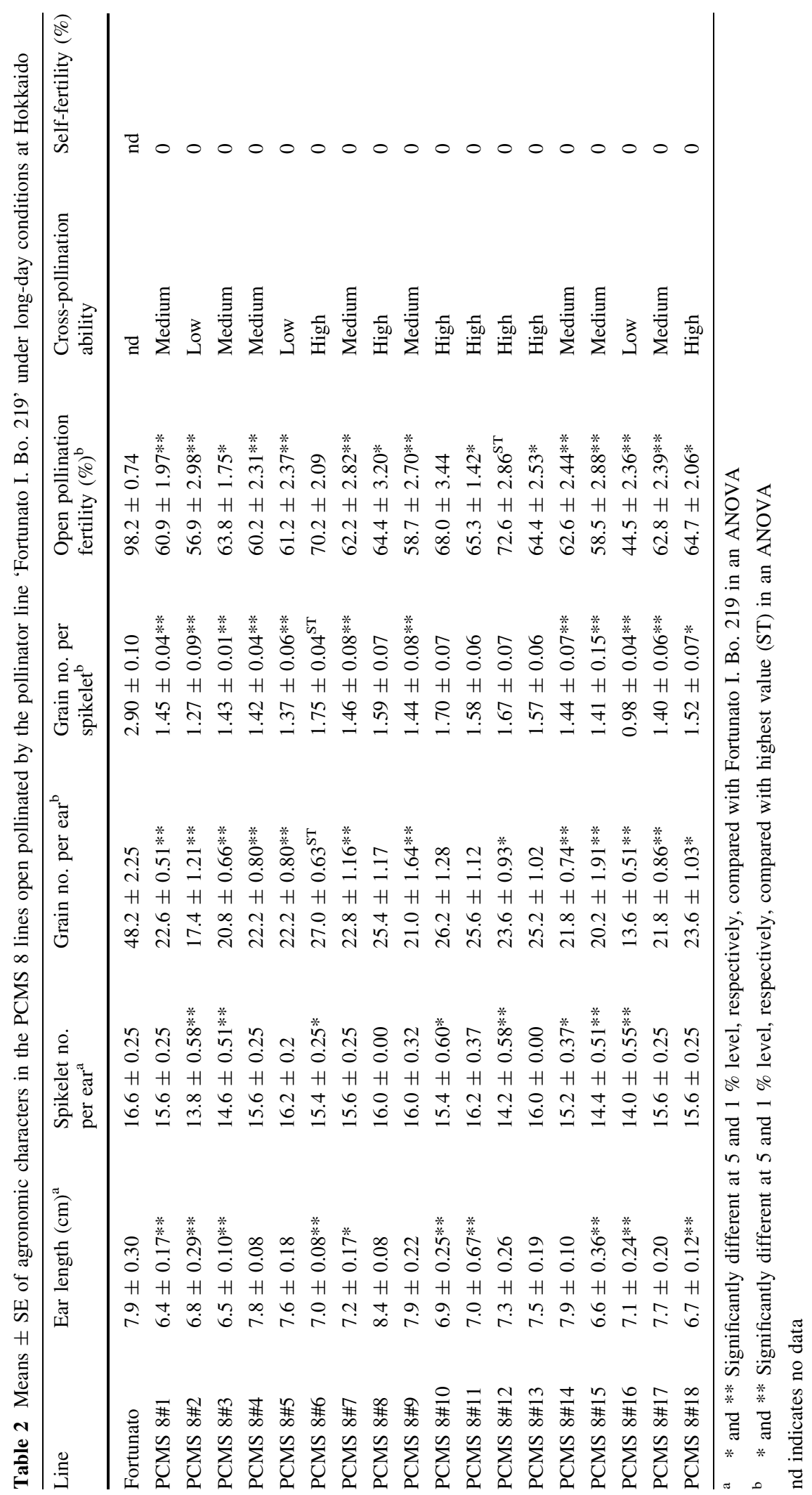


Table 3 Means \pm SE for agronomic characters in the PCMS 8 lines self-pollinated under short-day conditions at Fukui

\begin{tabular}{|c|c|c|c|c|c|c|}
\hline Line & Culm length $(\mathrm{cm})^{\mathrm{b}}$ & Ear length $(\mathrm{cm})^{\mathrm{a}}$ & $\begin{array}{l}\text { Spikelet no. } \\
\text { per ear }^{\mathrm{a}}\end{array}$ & $\begin{array}{l}\text { Grain no. } \\
\text { per ear }^{b}\end{array}$ & $\begin{array}{l}\text { Grain no. } \\
\text { per spikelet }\end{array}$ & Self-fertility $(\%)^{b}$ \\
\hline Fukuotome & nd & $8.4 \pm 0.24$ & $16.7 \pm 0.42$ & $61.5 \pm 3.27$ & $3.68 \pm 0.13$ & $98.4 \pm 1.12$ \\
\hline PCMS 8\#1 & $63 \pm 1.2$ & $7.5 \pm 0.09 * *$ & $15.4 \pm 0.30^{*}$ & $44.3 \pm 3.05$ & $2.81 \pm 0.18$ & $83.1 \pm 3.69$ \\
\hline PCMS 8\#2 & $64 \pm 2.3$ & $8.7 \pm 0.16$ & $16.6 \pm 0.20$ & $43.9 \pm 5.87$ & $2.91 \pm 0.35$ & $80.3 \pm 6.71$ \\
\hline PCMS 8\#3 & $63 \pm 1.4$ & $8.3 \pm 0.26$ & $16.2 \pm 0.48$ & $54.7 \pm 6.29^{\mathrm{ST}}$ & $3.22 \pm 0.34^{\mathrm{ST}}$ & $87.0 \pm 6.08$ \\
\hline PCMS 8\#4 & $55 \pm 1.9 * *$ & $7.6 \pm 0.35^{*}$ & $15.7 \pm 0.57$ & $28.7 \pm 5.42 * *$ & $1.97 \pm 0.37 * *$ & $63.6 \pm 8.88^{* *}$ \\
\hline PCMS 8\#5 & $66 \pm 1.3$ & $8.1 \pm 0.17$ & $15.9 \pm 0.34$ & $32.4 \pm 5.59 * *$ & $2.02 \pm 0.34 * *$ & $61.3 \pm 10.78 * *$ \\
\hline PCMS 8\#6 & $65 \pm 1.3$ & $7.9 \pm 0.19$ & $16.3 \pm 0.33$ & $42.5 \pm 2.46$ & $2.73 \pm 0.20$ & $81.2 \pm 4.76$ \\
\hline PCMS 8\#7 & $65 \pm 1.5$ & $7.6 \pm 0.17 *$ & $15.7 \pm 0.18$ & $40.3 \pm 4.92 *$ & $2.62 \pm 0.32$ & $81.0 \pm 7.32$ \\
\hline PCMS 8\#8 & $61 \pm 2.1^{*}$ & $8.3 \pm 0.24$ & $16.2 \pm 0.37$ & $50.8 \pm 4.26$ & $3.13 \pm 0.21$ & $85.6 \pm 4.16$ \\
\hline PCMS 8\#9 & $65 \pm 1.9$ & $8.6 \pm 0.28$ & $16.5 \pm 0.29$ & $36.3 \pm 4.21 *$ & $2.25 \pm 0.22^{*}$ & $71.8 \pm 4.89$ \\
\hline PCMS 8\#10 & $62 \pm 0.9^{*}$ & $7.7 \pm 0.19 *$ & $16.0 \pm 0.19$ & $47.8 \pm 2.09$ & $3.02 \pm 0.15$ & $89.6 \pm 2.96^{\mathrm{ST}}$ \\
\hline PCMS 8\#11 & $62 \pm 2.2^{*}$ & $7.7 \pm 0.19 *$ & $16.6 \pm 0.37$ & $38.0 \pm 4.73 * *$ & $2.36 \pm 0.27 *$ & $77.3 \pm 6.30$ \\
\hline PCMS 8\#12 & $67 \pm 0.9^{S T}$ & $8.4 \pm 0.16$ & $16.3 \pm 0.25$ & $49.8 \pm 3.28$ & $3.00 \pm 0.16$ & $86.0 \pm 2.94$ \\
\hline PCMS 8\#13 & $63 \pm 1.7$ & $7.8 \pm 0.17$ & $16.0 \pm 0.22$ & $38.9 \pm 4.22 *$ & $2.40 \pm 0.27^{*}$ & $74.4 \pm 6.29$ \\
\hline PCMS 8\#14 & $62 \pm 0.9^{*}$ & $8.0 \pm 0.28$ & $16.0 \pm 0.38$ & $41.1 \pm 3.58^{*}$ & $2.52 \pm 0.19$ & $81.4 \pm 4.78$ \\
\hline PCMS 8\#15 & $62 \pm 0.7^{*}$ & $7.2 \pm 0.13 * *$ & $15.7 \pm 0.18$ & $38.3 \pm 3.38^{*}$ & $2.36 \pm 0.20^{*}$ & $78.9 \pm 5.17$ \\
\hline PCMS 8\#16 & $65 \pm 1.0$ & $8.0 \pm 0.15$ & $15.7 \pm 0.29$ & $40.1 \pm 4.31 *$ & $2.46 \pm 0.28^{*}$ & $78.0 \pm 5.37$ \\
\hline PCMS 8\#17 & $62 \pm 1.1^{*}$ & $7.9 \pm 0.16$ & $15.3 \pm 0.37 * *$ & $48.9 \pm 3.26$ & $2.78 \pm 0.16$ & $86.9 \pm 2.97$ \\
\hline PCMS 8\#18 & $57 \pm 2.0 * *$ & $8.0 \pm 0.53$ & $16.0 \pm 0.68$ & $28.2 \pm 4.07 * *$ & $1.72 \pm 0.25^{* *}$ & $63.5 \pm 8.77 * *$ \\
\hline
\end{tabular}

Data for 'Fukuotome' were obtained from open-pollinated ears

a $*$ and ** Significantly different at 5 and $1 \%$ level, respectively, compared with 'Fukuotome' in an ANOVA

b $*$ and ** Significantly different at 5 and $1 \%$ level, respectively, compared with highest value (ST) in an ANOVA

nd indicates no data

Table 4 Means \pm SE for seed characters of the PCMS 8\#12 line compared with the normal line 'Fortunato I. Bo. 219'

\begin{tabular}{lll}
\hline Line & 1000 grain weight $(\mathrm{g})$ & Volume weight $(\mathrm{g} / \mathrm{L})$ \\
\hline PCMS 8\#12 & $40.4 \pm 0.93$ & $623 \pm 13.6$ \\
Fortunato I. Bo. 219 & $38.3 \pm 1.31$ & $510 \pm 18.6$ \\
$t$ value & $1.2924 \mathrm{~ns}$ & $4.8412 * *$ \\
\hline
\end{tabular}

** Significantly different at $1 \%$ level in a $t$ test

Kitami-haru 63, Fortunato I. Bo. 219, Aroora, and Wildcat) were not significant (Fig. 2). Three of them, (cr)-Yumeshiho, (cr)-Forutunato I. Bo. 219 and (cr)Aroora, showed the large grain number per spikelet as much as those in the corresponding euplasmic lines, suggesting that they contain strong $R f$ gene(s) against the PCMS lines. Heading date of Fortunato I. Bo. 219 was closest to that of (cr)-Fukuotome (Fig. 2). This suggests that Fortunato I. Bo. 219 is a most suitable as a pollinator line for the PCMS lines with Fukuotome genetic background.

\section{Discussion}

Hybrid wheat breeding systems are classified into four categories based on the method of fertility control: chemical hybridizing agents (CHAs); cytoplasmic male sterility (CMS); genic male sterility (GMS); and, genetic modification (GM) systems. The CHA system is a comparatively easy approach for developing hybrid wheat varieties because it does not require the development of three parental lines (a male sterile line with CMS cytoplasm, a maintainer line with 


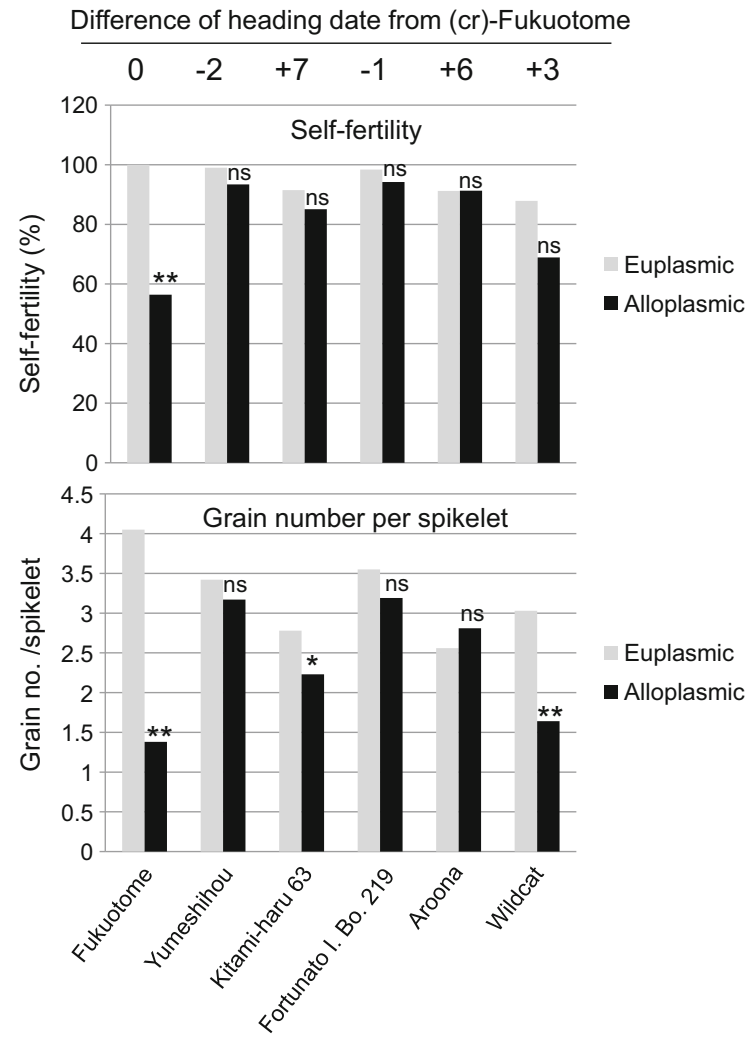

Fig. 2 Self-fertility and grain number per spikelet in the euplasmic and alloplasmic lines of Yumeshiho, Kitami-haru 63, Fortunato I. Bo. 219, Aroora, and Wildcat, compared with those of Fukuotome. ${ }^{*}$ and $* *$ indicate significantly different at $5 \%$ and $1 \%$, respectively, between euplasmic and alloplasmic lines. The differences of heading date compared with (cr)Fukuotome are indicated on the top of figure

normal cytoplasm, and a restorer line with an $R f$ gene). There is, however, still a problem of toxicity of CHAs; Croisor 100, provided by Saaten-Union, is the only CHA currently used for commercial hybrid seed production (Longin et al. 2012; Whitford et al. 2013). The CMS system is superior to the CHA system in seed production costs. However, the standard CMS system uses the cytoplasm of T. timopheevii, which has deleterious effects (Pickett 1993; Edwards 2001). Other CMS systems using A. kotschyi, A. mutica or A. uniaristata cytoplasm have been proposed and recently the $R f$ genes against these cytoplasms were identified in 1BS-1RS recombinant lines (Tsunewaki 2015); however, the utility of these alternative CMS systems is still unknown. A photothermo-sensitive GMS variety has been developed in China, but there are limited fertility restoring lines
(Sun et al. 2001). A cytogenetic method using an additional chromosome 4E from Elytrigia elongate (Zhou et al. 2006) and an XYZ system using a nonconditional GMS mutant (Driscoll 1972) have been proposed but not used in practice. As detailed in the CIMMYT report, there is a need for the development of cost-effective and simple systems to allow worldwide expansion of hybrid wheat cultivation. Recently, several systems using genetic modification (GM) for hybrid breeding have been proposed (Whitford et al. 2013). Although molecular genetic-based technologies might improve hybrid production systems and reduce hybrid seed production costs, it is still not known whether GM systems for hybrid breeding would be accepted by consumers.

In a previous study, we reported that an alloplasmic line of the Japanese wheat cv. 'Norin 26', which carried the cytoplasm of A. crassa, showed PCMS (Murai and Tsunewaki 1993). This alloplasmic line was extensively studied in an attempt to utilize it for hybrid wheat breeding (Murai 2001a). Japanese wheat cultivars were classified into two groups based on the effect of $A$. crassa cytoplasm: carriers or non-carriers of the $R f$ gene against this cytoplasm (Murai and Tsunewaki 1995). For example, 'Norin 26' and 'Fujimikomugi' are $R f$ non-carrier cultivars, and 'Norin 61' and 'Ushiokomugi' are $R f$ carriers. Genetic analysis indicated that 'Norin 61' has multiple $R f$ genes located on at least four chromosomes, namely, 4A, 1D, 3D, and 5D (Murai 1997b). By recurrent backcrossing, we produced several alloplasmic lines of $R f$ non-carrier cultivars as PCMS lines (Murai and Tsunewaki 1995). $\mathrm{F}_{1}$ hybrids between the PCMS lines and $R f$ carrier cultivars showed high restoration of fertility, indicating that the $R f$ genes were effective in the PCMS system for hybrid wheat breeding (Murai 1997a). We also reported two other types of $R f$ gene against PCMS. The first was a single dominant $R f$ gene in the cultivar 'Chinese Spring' located on the long arm of chromosome 7B; however, additional modifiers were present (Murai and Tsunewaki 1994; Murai et al. 2002). The second was a recessive $R f$ gene in a fertility-restoring mutant of alloplasmic 'Norin 26' (Murai et al. 1995). These findings suggest that PCMS induction and fertility restoration is a complicated phenomenon.

In this study, we developed several PCMS lines with Fukuotome genetic background. The PCMS lines are soft red spring wheat. As the pollinator lines for the 
PCMS system, we screened hard red spring wheat cultivars. Hybrid wheat varieties between soft red wheat and hard red wheat produce wheat flour with middle property of soft wheat and hard wheat. Such hybrid wheat flour should be suitable for Japanese thin noodle, somen. In a screening of pollinator lines for the PCMS system, we found that Italian hard red wheat cultivar 'Fortunato I. Bo. 219' contained $R f$ gene(s) that was/were effective in fertility restoration against the PCMS; this cultivar was used as a pollinator line in this study.

Our previous studies revealed that the levels of male sterility under LD conditions and male fertility under SD conditions in PCMS lines are determined by the genotype of the nuclear donor. For example, the PCMS line cv. 'Norin 26' ((cr)-Norin 26) shows partial male sterility under LD conditions (Murai and Tsunewaki 1993; Murai 1998, 2001b), whereas that of cv. 'Fujimikomugi' ((cr)-Fujimikomugi) is completely male sterile under LD conditions (Murai and Tsunewaki 1995; Murai 2001b). However, PCMS cultivar 'Fujimikomugi' shows lower female fertility under LD conditions (Murai 2001b), and lower seed setting under SD conditions (Murai and Tsunewaki 1995).

PCMS lines that show high male sterility under LD conditions and high seed setting under SD conditions were developed in a previous study by screening the progeny of the $F_{1}$ between '(cr)-Norin 26' and 'Fujimikomugi' after backcrossing to the elite wheat cultivar 'Fukuotome' (Murai et al. 2008). This screen identified two PCMS lines, namely, (cr)-Norin 26/Fujimikomugi//3*Fukuotome \#6(11)-3 and \#7(12)-2, which were renamed here as PCMS 7 line and PCMS 8 line, respectively. These PCMS lines were from a $\mathrm{BC}_{2}$ generation and were not genetically pure lines. By selfing and screening the progenies from lines PCMS 7 and PCMS 8 in the experimental field of Fukui Prefectural University, we developed $32 \mathrm{BC}_{2} \mathrm{~F}_{8}$ lines, PCMS 7\#1-14 and PCMS 8\#1-18. An important factor that contributes to the success of a hybrid wheatbreeding program is the efficient production of $F_{1}$ seeds by crossing a male sterile line with a pollen parent. In this study, we examined the agronomic characters of the $32 \mathrm{BC}_{2} \mathrm{~F}_{8}$ lines under $\mathrm{LD}$ conditions at Hokkaido and under SD conditions at Fukui. Based on the data, we selected eight promising PCMS lines that showed high cross-pollination ability under LD conditions, high male sterility under LD conditions and high seed setting under SD conditions. These PCMS elite lines will be useful for developing hybrid wheat varieties. In the next step, combining ability of the PCMS lines with the efficient pollinator lines such as 'Fortunato I. Bo. 219' will be examined.

Acknowledgments $\mathrm{We}$ are grateful to the National Bioresource Project-Wheat (NBRP-KOMUGI) for providing wheat materials. This work was supported by JSPS KAKENHI Grant Number JP21380009. This work was also supported in part by a Grant-in-Aid (D) from Fukui Prefectural University to K. Murai.

Open Access This article is distributed under the terms of the Creative Commons Attribution 4.0 International License (http:// creativecommons.org/licenses/by/4.0/), which permits unrestricted use, distribution, and reproduction in any medium, provided you give appropriate credit to the original author(s) and the source, provide a link to the Creative Commons license, and indicate if changes were made.

\section{References}

CIMMYT (2011) Wheat-global alliance for improving food security and the livelihoods of the resource-poor in the developing world. Proposal submitted by CIMMYT and ICARDA to the CGIAR Consortium Board

Driscoll CJ (1972) XYZ system of producing hybrid wheat. Crop Sci 12:516-517

Edwards IB (2001) Hybrid wheat. In: Bonjean AP, Angus WJ (eds) The world wheat book: a history of wheat breeding. Lavoisier Publishing, Paris, pp 1017-1045

Johnson VA, Schmidt JW (1968) Hybrid wheat. Adv Agron 20:199-233

Longin CFH, Muhleisen J, Maurer HP, Zhang H, Gowda M, Reif JC (2012) Hygbrid breeding in autogamous cereals. Theor Appl Genet 125:1087-1096

Murai K (1997a) Effects of Aegilops crassa cytoplasm on the agronomic characters in photoperiod-sensitive CMS wheat lines and $F_{1}$ hybrids. Breed Sci 47:321-326

Murai K (1997b) Genetic analysis of fertility restoration against photoperiod-sensitive cytoplasmic male sterility in Triticum aestivum cv. Norin 61. Plant Breed 116:592-594

Murai K (1998) $F_{1}$ seed production efficiency by using photoperiod-sensitive cytoplasmic male sterility and performance of $F_{1}$ hybrid lines in wheat. Breed Sci 48:35-40

Murai K (2001a) Genetic effects of an alien cytoplasm on male and female fertility in wheat. Recent Res Devel Genet $1: 47-54$

Murai K (2001b) Factors responsible for levels of male sterility in photoperiod-sensitive cytoplasmic male sterile (PCMS) wheat lines. Euphytica 117:111-116

Murai K, Tsunewaki K (1993) Photoperiod-sensitive cytoplasmic male sterility in wheat with Aegilops crassa cytoplasm. Euphytica 67:41-48 
Murai K, Tsunewaki K (1994) Genetic analysis on the fertility restoration by Triticum aestivum $\mathrm{cv}$. Chinese spring against photoperiod-sensitive cytoplasmic male sterility. Jpn J Genet 69:195-202

Murai K, Tsunewaki K (1995) Photoperiod-sensitive cytoplasmic male sterility induced in Japanese wheat cultivars by transferring Aegilops crassa cytoplasm. Breed Sci 45:199-203

Murai K, Ogihara Y, Tsunewaki K (1995) An EMS-induced wheat mutant restoring fertility against photoperiod-sensitive cytoplasmic male sterility. Plant Breed 114:205-209

Murai K, Takumi S, Koga H et al (2002) Pistillody, homeothic transformation of stamens into pistil-like structures, caused by nuclear-cytoplasm interaction in wheat. Plant $\mathrm{J}$ 29:169-181

Murai K, Tsutui I, Kawanishi Y, Ikeguchi S, Yanaka M, Ishikawa N (2008) Development of photoperiod-sensitive cytoplasmic male sterile (PCMS) wheat lines showing high male sterility under long-day conditions and high seed fertility under shortday conditions. Euphytica 159:315-323

Pickett AA (1993) Hybrid wheat-results and problems, vol 15. Advances in plant breeding. Paul Parey Scientific, Berlin

Sun B, Zhang A, Bonjean AP (2001) Chinese wheat pool. In: Bonjean AP, Angus WJ (eds) The world wheat book: a history of wheat breeding. Lavoisier Publishing, Paris, pp 667-701

Tsunewaki K (2015) Fine mapping of the first multi-fertilityrestoring gene, $R f^{\text {multi }}$, of wheat for three Aegilops plasmons, using 1BS-1RS recombinant lines. Theor Appl Genet 128:723-732

Whitford R, Fleury D, Reif JC, Garcia M, Okada T, Korzun V, Langridge P (2013) Hybrid breeding in wheat: technologies to improve hybrid wheat seed production. J Exp Bot 18:5411-5428

Zhou K, Wang S, Feng Y et al (2006) The 4E-ms system of producing hybrid wheat. Crop Sci 46:250-255 